\title{
MANDIBULAR SECOND MOLAR IMPACTION - LITERATURE REVIEW AND CASE REPORTS
}

\author{
Deyan Neychev, Ivan Chenchev, Dimitar Atanasov
}

\author{
Department of Oral Surgery, Faculty of Dental Medicine, Medical University - Plovdiv
}

\begin{abstract}
AIM: To assess the incidence of mandibular second molar impaction and the treatment methods for this condition.

MATERIALS AND METHODS: A retrospective review of the cases of patients diagnosed with impaction of mandibular molars at the Department of Oral Surgery of the Faculty of Dental Medicine - Plovdiv during the past 11 years was performed.

RESULTS: 962 patients with impaction of mandibular molars were operated on in the analyzed period. This diagnosis is relatively rare in second mandibular molars and represents $0.94 \%$ of all cases. Most often, diagnosis is based on clinical evidence of missing molars and on panoramic radiographs. In the cases described by us, only surgical treatment was used.
\end{abstract}

CONCLUSION: The treatment of this condition is a challenge which requires an individual approach to each case and an assessment to determine what treatment approach is to be used - surgical or orthodontic.

Keywords: mandibular second molar impaction, surgical treatment

\section{INTRODUCTION}

Tooth impaction is common, and it may affect each tooth of the dental arch. A study of 3,874 radiographs found prevalence of impaction of about $17 \%$ (1). Teeth most commonly affected by this abnormality in order of prevalence are as follows: mandibular and maxillary third molars, maxillary canines and mandibular second molars. Mandibular second molar impaction is much rarer than third molar im-

\footnotetext{
Address for correspondence:

Deyan Neychev

Department of Oral Surgery

Faculty of Dental Medicine

Medical University - Plovdiv

$3 \mathrm{Hr}$. Botev St

4000 Plovdiv

e-mail:dneitchev@yahoo.com
}

Received: April 8, 2017

Accepted: May 22, 2017 paction. According to literature data, the prevalence of impacted second molars is as high as about 2.3\% $(2,3,4)$. A recent study shows that the prevalence of mandibular second molar impaction is about $1.36 \%$ (5). According to some authors, unilateral mandibular second molar impaction is more common than the bilateral one. This abnormality is more common in females (6).

According to the classification by Andreasen and Kurol (7), the absence of eruption of mandibular second molars is due to the following three reasons:

1. Impaction - due to a physical obstacle or lack of space. It can also be caused by extra teeth, odontomas or other odontogenic tumors.

2. Primary retention - eruption hindered before gingival emergence. A physical obstacle or ectopic eruption cannot be found. In most of the cases, the reasons for this retention are unknown. According to literature data, in some 
Deyan Neychev, Ivan Chenchev, Dimitar Atanasov

cases such retention is due to syndromes with osteoclastic activity abnormalities (6).

3. Secondary retention - cessation of eruption of a tooth after gingival emergence without evidence of physical obstacle. This type of retention is more common than primary retention. It may be caused by small areas of ankylosis. In $81 \%$ of the cases these areas are located at the bifurcation and interradicular root surface (8).

The lack of sufficient space is considered a major factor for tooth impaction and especially for mandibular second molar impaction (9). According Varpio and Wellfelt (10), local insufficiency of space is observed in $90 \%$ of cases. These authors found that most of impacted second molars were in mesio-angular position. This is confirmed by studies of other authors (11).

Many pathological processes can result in tooth impaction. They include odontogenic keratocysts, ameloblastomas, odontomas and other cysts and tumors (3).

In rare cases, molar impaction is a manifested symptom of a general disease - cleidocranial dysplasia (12), GAPO syndrome (13) (a complex of symptoms including growth retardation, alopecia, pseudoanodontia and progressive optic atrophy), GorlinGoltz syndrome (14) (autosomal-dominant inherited disorder characterized by the presence of multiple odontogenic keratocysts as well as the presence of visual, dermal, neurological and others abnormalities), etc. According to literature data, impaction of mandibular second molars may be due to an excess space between the first and the second molars, as the eruption of the second molar is dependent on the first molar roots (15).

Impacted mandibular second molars are diagnosed accidentally by a routine panoramic radiograph or in the course of orthodontic treatment. The radiograph shows both the position of the tooth relative to the adjacent teeth, and the angulation and presence of resorption of the adjacent teeth (16).

According to Magnusson et al. (17), indications for treatment of impacted second molars take into account the risk of caries of adjacent teeth, follicular cysts, resorption of adjacent teeth, occlusal abnormalities, etc. Some authors found relationship between second molar impaction and "crowding", which is also an indication for treatment.

Treatment of such teeth requires a multidisciplinary approach - an option for surgical treatment can be chosen depending on the particular case:

1. extraction of the impacted second and third molars;

2. extraction of the third molar with subsequent surgical repositioning of the second molar there is a risk of loss of vitality, root resorption and ankylosis $(18,19)$;

3. surgical uncovering of the impacted second molar with subsequent orthodontic treatment (20).

\section{MATERIALS AND METHODS}

A retrospective study of the cases of the patients treated at the Department of Oral Surgery - Plovdiv in the period 2004 - 2014 was performed. 962 patients diagnosed with mandibular molar impaction were operated on. Of these, 57\% were female and $43 \%$ were male. In the entire period studied, only 9 patients with impacted mandibular second molars were found, which represents $0.94 \%$ of all operated patients. Of these, five were female and four were male. All patients with mandibular second molar impaction underwent surgical treatment only.

\section{Case Report 1}

A 17-year-old boy with complaints of missing right mandibular molars was referred for treatment to the Department of Oral Surgery of the Faculty of Dental Medicine - Plovdiv. The panoramic radiograph showed impacted right-sided second and third molars without any concomitant abnormalities. Intraorally, lack of molars 46, 47 and 48 was found. The

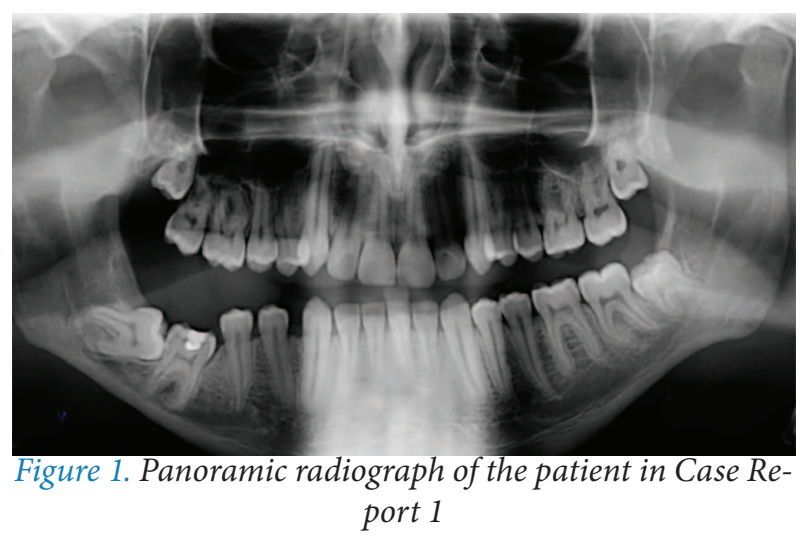


mucosa in the molar region was pale pink, with no evidence of inflammatory processes. The treatment plan included removal of molar 47 because orthodontic correction was not possible. Treatment was carried out as a single surgical procedure.

\section{Case Report 2}

A 22-year-old male patient from the city of Plovdiv, referred for consultation and treatment to the Department of Oral Surgery of the Faculty of Dental Medicine - Plovdiv.

He had complaints of missing mandibular molars bilaterally. Panoramic radiograph showed bilateral impaction of teeth 37 and 38, and 47 and 48 . No pathological processes in the bone structures were found. Intraoral examination showed lack of second and third mandibular molars bilaterally. There was no clinical evidence of soft tissue inflammation. Treatment plan included removal of mandibular third molars only. Treatment was performed in two stages.

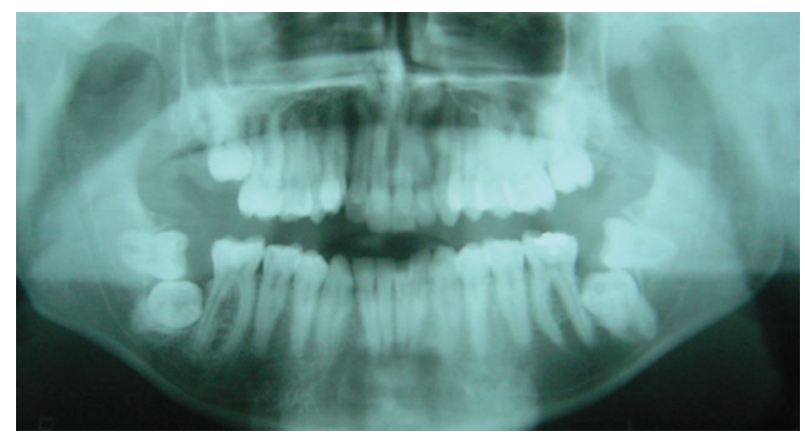

Figure 2. Panoramic radiograph of the patient in Case Report 2

\section{Surgical Treatment}

Mandibular nerve block was performed with a $4 \%$ solution of articaine hydrochloride with epinephrine concentration of 1:100000. It was decided to raise a triangular flap, because it was appropriate for deeper teeth. A horizontal incision was performed, reaching the distal part of the last erupted tooth, then continuing in a vertical incision, running obliquely downwards and forward, and ending in the vestibular arch (21). After raising the flap, fenestration of the bone with a round bur was performed, then the bone opening was extended using a cutter and the tooth was exposed. Dislocation and extraction of the third molars followed. The mandibular second mo- lars were exposed. Bone edges were smoothened and revision of the wound was performed. Sutures were placed for 7 days. Instructions were given to the patient to take care of the surgical wound. Analgesics were prescribed. No complications occurred in the postoperative period.

\section{DISCUSSION}

Treatment of impacted mandibular second molars is a challenge because of the small prevalence of this abnormality and the difficulties in determining its etiology. According to some authors, positive results from the treatment of this abnormality can be expected if the cases are diagnosed early and treated promptly $(11,22)$. According to García-Calderón et al. (23), the most successful approach for treating impacted mandibular second molars would be orthodontic treatment. However, it cannot be used in deeper impacted teeth. In the patients operated on by us, surgical treatment was leading. According to the classification by Andreasen and Kurol (7), both cases presented by us are cases of impaction. Therefore, removal of the physical obstacle causing the absence of eruption of mandibular second molars was needed. Third molars were removed surgically, and impacted second molars were exposed and were left to erupt spontaneously. In the second case, treatment was carried out in two stages.

According to Magnusson et al. (17), this surgical approach gives best results (71\%). The above study found that the exposed second molars which were left to erupt erupted spontaneously in about $50 \%$ of the cases. In the absence of spontaneous eruption, orthodontic treatment may be of benefit.

\section{CONCLUSION}

Treatment of impacted mandibular second molars is a serious challenge for oral surgeons and orthodontists. In a significant part of the studies on this matter, surgical treatment is leading. Early diagnosis and proper treatment approach planning determine the final results. Collaboration between the oral surgeon and the orthodontist ensures the most adequate treatment approach and optimal outcome.

\section{REFERENCES}

1. Dachi SF, Howell FV. A survey of 3,874 routine fullmonth radiographs. II. A study of impacted teeth. 
Deyan Neychev, Ivan Chenchev, Dimitar Atanasov

Oral Surg Oral Med Oral Pathol. 1961;14:1165-9. doi: 10.1016/0030-4220(61)90204-3

2. Bondemark L, Tsiopa J. Prevalence of ectopic eruption, impaction, retention and agenesis of the permanent second molar. Angle Orthod. 2007;77(5):773-8. doi: 10.2319/072506-306.1

3. Tsukamoto G, Makino T, Kikuchi T, Kishimoto K, Nishiyama A, Sasaki A, et al. A comparative study of odontogenic keratocysts associated with and not associated with an impacted mandibular third molar. Oral Surg Oral Med Oral Pathol Oral Radiol Endod. 2002; 94(2): 272-5. doi: 10.1067/ moe.2002.126888

4. Vedtofte H, Andreasen JO, Kjaer I. Arrested eruption of the permanent lower second molar. Eur J Orthod. 1999; 21(1): 31-40. doi: 10.1093/ejo/21.1.31

5. Cassetta M, Altieri F, Di Mambro A, Galluccio G, Barbato E. Impaction of permanent mandibular second molar: A retrospective study. Med Oral Patol Oral Cir Bucal. 2013; 18(4):564-8. doi: 10.4317/ medoral.18869

6. Oliver RG, Richmond S, Hunter B. Submerged permanent molars: four case reports. Br Dent J.1986;160(4):128-30.

7. Andreasen JO, Kurol J. The impacted first and second molar. In: Andreasen JO, Petersen JK, editors. Textbook and color atlas of tooth impactions. Copenhagen: Munksgaard; 1977. 197-218.

8. Raghoebar GM, Boering G, Jansen HW, Vissink A. Secondary retention of permanent molars: a histologic study. J Oral Pathol Med. 1989 ;18(8): 427-31. doi: 10.1111/j.1600-0714.1989.tb01338.x

9. Johnson JV, Quirk GP. Surgical repositioning of impacted mandibular second molar teeth. Am J Orthod Dentofac Orthop. 1987;91(3): 242-51. doi: 10.1016/0889-5406(87)90454-9

10. Varpio M, Wellfelt B. Disturbed eruption of the lower second molar: clinical appearance, prevalence, and etiology. ASDC J Dent Child. 1988; 55(2):114-8.

11. Valmaseda-Castellon E, De-la-Rosa-Gay C, GayEscoda C. Eruption disturbances of the first and second permanent molars: results of treatment in 43 cases. Am J Orthod Dentofacial Orthop. 1999; 116(6): 651-8. doi: 10.1016/S0889-5406(99)70200-3

12. Arvystas M.G.: Familial generalized delayed eruption of the dentition with short stature. Oral Surg Oral Med Oral Pathol. 1976; 41(2):235-43. doi: $10.1016 / 0030-4220(76) 90235-8$
13. Tipton RE, Gorlin RJ. Growth retardation, alopecia, pseudo-anodontia, and optic atrophy - the GAPO syndrome:report of a patient and review of the literature. Am J Med Genet. 1984; 19(2): 20916. doi: 10.1002/ajmg.1320190202

14. Gorlin RJ, Goltz RW. Multiple nevoid basal-cell epithelioma, jaw cysts and bifid rib: a syndrome. N Engl J Med. 1960; 262: 908-12. doi: 10.1056/ NEJM196005052621803

15. Shapira Y, Borell G, Nahlieli O, Kuftinec MM. Uprighting mesially impacted mandibular permanent second molars. Angle Orthod. 1998; 68(2): 173-8.

16. Jung $\mathrm{YH}, \mathrm{Cho} \mathrm{BH}$. Prevalence of missing and impacted third molars in adults aged 25 years and above. Imaging Sci Dent. 2013; 43(4): 219-25. doi: 10.5624/isd.2013.43.4.219

17. Magnusson $\mathrm{C}$, Kjellberg H. Impaction and retention of second molars: diagnosis, treatment and outcome. A retrospective follow-up study. Angle Orthod. 2009; 79(3): 422-7. doi: 10.2319/021908-97.1

18. Frank CA. Treatment options for impacted teeth. J Am Dent Assoc. 2000; 131(5): 623-32. 10.14219/ jada.archive. 2000.0236

19. McAboy CP, Grumet JT, Siegel EB, Iacopino AM. Surgical uprighting and repositioning of severely impacted mandibular second molars. J Am Dent Assoc. 2003 ;134(11):1459-62. 10.14219/jada. archive.2003.0074

20. Sawicka M, Racka-Pilszak B, Rosnowska-Mazurkiewicz A. Uprighting Partially Impacted Permanent Second Molars. Angle Orthod. 2007; 77( 1): 148-54. doi: 10.2319/010206-461R.1

21. Atanasov D. Oral Surgery. Plovdiv: Taf print; 2011.

22. Shpack N, Finkelstein T, Lai YH, Kuftinec MM, Vardimon A, Shapira Y. Mandibular Permanent Second Molar Impaction Treatment options and outcome. Open J Dent Oral Med. 2013;1(1): 9-14. doi: 10.13189/ojdom.2013.010103

23. García-Calderón M, Torres-Lagares D, GonzálezMartín M, Gutiérrez-Pérez JL. Rescue surgery (surgical repositioning) of impacted lower second molars. Med Oral Patol Oral Cir Bucal 2005;10(5):448-53. 